\section{Vadilene Cruz}

Luis Mendes ${ }^{1}$

Article info:

Received 29.11.2018

Accepted 04.03.2019

UDC - 366.626

DOI - 10.24874/IJQR13.02-08

\section{THE INFLUENCE OF SERVICE QUALITY ON USERS' BEHAVIOURAL INTENTIONS IN DEVELOPING COUNTRIES: A CROSS- SECTIONAL STUDY IN CAPE VERDE'S PUBLIC HOSPITALS}

\begin{abstract}
The study analyses the influence of perceived service quality and patients' satisfaction on behavioral intentions, as well as the role of the institutional image in this chain of relations, studying also the applicability of the PAKSERV scale in the Cape Verdean health care context. Data collection was conducted through a self-administered questionnaire applied to emergency services users in two public hospitals in Cape Verde. Results of a structural equation modelling approach confirm the influence of perceived service quality and patients' satisfaction on behavioral intentions, as well as a partial mediation role of the institutional image. Findings also suggest the applicability of the PAKSERV scale in the context explored. This research contributes to the development of service management theory, first, testing the PAKSERV scale both in a different geographical context (Cape Verde), and in a different sectorial context (public hospitals), and second, analyzing the influence of service quality and users' satisfaction on behavioral intentions in the context of emergency services in Cape Verde's public hospitals.
\end{abstract}

Keywords: Service quality, patient satisfaction, behavioral intention, heath care service

\section{Introduction}

Quality has stand out as a critical success and survival factor for any organization, thus representing a strong concern in most service sectors, especially in the context of health care, since it involves transversely, all procedures, from patients' reception to all the services provided by professionals. Considering such a panorama, the adoption of quality management practices and systems has been a strategy followed in many countries (mainly industrialized), for which there is an extensive literature available, including in the health care context, where the search for continuous initiatives to improve the quality of health services is a growing priority.

Generally recognized as a key issue in organizations' efforts to differentiate from competitors, service quality has been shown to influence significantly customers' perceived value, and satisfaction, allowing a greater loyalty, customer retention and attraction and, ultimately, enhanced profitability, among other potential benefits (Malik, 2012; Tu et al., 2011; Kang \& James, 2004).

\footnotetext{
${ }^{1}$ Corresponding author: Luís Mendes Email: lmendes@ubi.pt
} 
Previous studies have suggested that service quality is dependent on a strategic managerial decision based on a carefully balanced mix of three basic elements (e.g. Haywood-Farmer, 1993): i) Physical Facilities, Processes and Procedures (inc. location, layout, size, reliability, process flow, process flexibility, timeliness, or communication, among others), ii) People's Behaviour and Conviviality (inc. warmth, friendliness, attitude, neatness, politeness, attentiveness, handling complaints, or solving problems, among others), and iii) Professional Judgement (inc. diagnosis, advice, guidance, honesty, confidentiality, knowledge, skill, among others).

Indeed, service quality has become a hot issue for more than three decades, and although literature has addressed various issues related to service quality, most of research efforts has been targeted at the development of trustworthy and replicable tools to assess service quality. Among these efforts, several models have been developed such as the Nordic model proposed by Gronroos (1984), or Cronin and Taylor's (1992) SERVPERF model; in this context, the development of the SERVQUAL scale, by Parasuraman et al. (1985, 1988), subsequently refined by Parasuraman et al. (1991, 1994) was undoubtedly a significant milestone in the evolution of theory on service quality. Indeed, despite the several theoretical and empirical criticisms raised concerning the SERVQUAL scale (see Ladhari, 2009), the instrument remains the best-known and most used measure in service quality research.

However, concerning services in developing countries contexts, some researchers have reported that popular service quality assessment scales such as SERVQUAL or SERVPERF do not fit the reality of these countries (e.g. Malhotra et al, 2005). Considering cultural differences between Asian and Western societies, Raajpoot (2004) developed a culturally sensitive scale labelled PAKSERV to assess service quality in the Pakistani context, more appropriate for developing countries, and which has been applied and studied in Asian contexts, such as Thai higher education (Kashif, \& Cheewakrakokbit, 2018), Pakistani higher education (Kashif, Ramayah, \& Sarifuddin, 2016), Malaysian banking (Kashif et al., 2015), Pakistani Public Hospitals (Kashif et al., 2014), or Pakistani banking (Kashif et al., 2016), and even in South African banking (Saunders, 2008).

Nevertheless, despite the growing number of studies, most of these are focused on Western perspectives (e.g., Parasuraman et al., 1991; Parasuraman et al., 1988), and findings may not be generalized to other contexts (Murti et al., 2013). In fact, concerning developing countries there is a paucity of research in this area, especially in health care contexts, because the phenomenon has long been neglected by policy makers and managers in those countries, believing that quality assessment and assurance was a luxury confined to developed countries.

As a result, considering the context of Cape Verdean public hospitals, this study aimed to analyze the influence of perceived emergency services quality and patients' satisfaction on behavioral intentions, as well as the role of the institutional image in this chain of relations, studying for this purpose the applicability of the PAKSERV scale both in a new geographical context (Cape Verde), and in an underexplored sectorial context (public hospitals). This option was based on the idea that literature highlights that Western countries differ from non-Western countries in terms of behavior, norms and values (e.g. Hofstede, 1980), and thus, researchers need to be aware of cultural influences when assessing service (Ladhari, 2009).

Data collection was carried out through a questionnaire applied to patients in emergency services of Cape Verdean public hospitals and was carried out between June and July 2017. Results obtained from a twostage structural equation modelling analysis seem to confirm PAKSERV applicability to the context analyzed, and suggest not only that service quality has a positive direct effect 
on patients' satisfaction, which in turn influences behavioral intentions, but also that the organizational image plays a mediating role between service quality and satisfaction.

\section{Theoretical Background and Hypotheses development}

\subsection{Importance of service quality in the healthcare context}

Service quality has become a great differentiator and the most powerful weapon a service organization can possess. Considering the growing competition and increased customers' expectations, it becomes imperative for organizations to keep service quality in mind, as a guiding principle, because it has been identified as a key factor in building competitive advantages in the services sector.

In highly competitive industries, delivery of a higher service value is a prerequisite for survival, and thus, in accordance, maintaining high quality standards is a step towards success (Parasuraman et al., 1985, 1988). Indeed, organizations success is inherently linked to their ability both to identify and respond to customers' needs, and to understand and influence what is perceived as service quality by the target market. Thus, meeting customer expectations and meeting their needs are important elements in organizations' efforts to retain customers and gain competitive advantages over competitors (Parasuraman et al., 1988).

In such a context, and with a current market clearly oriented to customers, it is increasingly felt that quality will ultimately decide the value of a service provided, and hence has been largely adopted as a goal to be achieved (Ramanujam, 2011; Fradique, \& Mendes, 2013). Nevertheless, health care services have distinctive characteristics, especially considering the several critical risks involved (Rashid \& Jusoff, 2009).

Indeed, much pressure has been exerted on health organizations to improve their efficiency and quality of care provided to users (Sousa, 2006). However, the health care sector has to deal with demographic changes and population aging, with the increasing complexity of health care, with the emergence of new treatments and technologies, with increasing expectations of users and problems associated with financing, which condition not only the present, but also future sustainability (Sousa et al., 2008).

These challenges have been an incentive for a greater attention paid by managers and heads of both public and private healthcare institutions, concerning service quality issues and its assessment (Rashid, \& Jusoff, 2009; Sousa et al., 2008; Raposo et al., 2009; Mendes \& Fradique, 2014). However, the simultaneous pressures concerning costs control and higher quality of care has led to a misunderstanding about costs and potential compensations related to quality improvement initiatives (Carey \& Stefos, 2011). Recognizing that healthcare quality and its continuous improvement depend basically on good clinical practices and on how services are organized, the introduction of policies and strategies to improve quality in healthcare services can ensure the improvement of processes and the restructuring of services, in order to ensure an efficient use of resources and high levels of quality and safety required actually, because errors, mistakes, and bad practice in general represent serious problems for any organization, but especially in healthcare institutions, where such issues are often devastating (Sale, 1998).

According to the Institute of Medicine (IOM) (2000), in the United States of America, a significant number of patients died in hospitals as a result of preventative errors. Since then, these results have triggered a widespread awareness concerning user safety, reflected in a range of actions, including new laws, which have expanded worldwide to improve the quality of healthcare delivery (Carey \& Stefos, 2011; Institute of Medicine, 2001). 
The lack of quality and safety in healthcare organizations raises some important issues. For example, the occurrence of adverse events, whether due to medical error or to other reasons, causes damages to users, but also has significant social and financial consequences. These situations can lead to increased costs incurred from a greater use of resources to reverse damages caused to users, which may include more days of hospitalization, examinations, treatments or medication. In addition to costs, anothe $4 \mathrm{r}$ critical issue deals with loss of trust in organizations and their professionals, with a consequent degradation of relations between them and users (Sousa, 2006).

Thus, in order to strengthen a quality culture, significant advances have been pursued, based on the standardization of work processes, through services and units accreditation and certification practices (Sousa, 2006), which aims to officially recognize the quality of healthcare organizations and promote their voluntary commitment to continuous improvement, thus becoming increasingly important as an instrument for promoting and guaranteeing quality (Faria \& Mendes, 2013).

In this context, and especially due to societal pressures, it is extremely important to assess healthcare quality to make visible what goes on within organizations, the level of service quality, and what can be done to improve performance. In accordance, Bitner (1990), among many others, stressed the need to assess service quality from the client perspective; in fact, traditionally, managers have evaluated quality in terms of efficiency, neglecting the customer's perspective, although extremely important, considering that service quality is a determinant factor in consumers behavioral intention (Qin, 2009).

Literature has highlighted perceived quality as a critical variable that influences customers' perception of value, which in turn affects consumers' intentions to purchase products or services. The intangible nature of services dictates that, unlike products, most services are produced and consumed simultaneously, which increases the importance of the provider-consumer relationship, as well as potential variations in service quality. All these issues reflect the extreme importance of service quality in the context of healthcare units to turn them more sustainable and safer, and thus motivating their professionals to do their best to protect users, especially when these are vulnerable. In accordance, it is very important to develop a culture of self-assessment and constant search for processes improvement, valuing suggestions and ideas, but also criticism, of professionals and users, as a way to recognize that quality is a responsibility of all.

\subsection{Service quality assessment: SERVQUAL, SERVPERF A PAKSERV instruments}

Over the last decades, expectations are increasingly growing and thus services users are more and more exigent and selective. Furthermore, considering generalized high expenditures against available resources, the measurement of healthcare service quality has been a significant issue both for service providers and for governments.

The continuous search for excellence has led to the development of several models of service quality evaluation, among which we may highlight the SERVQUAL instrument, which was developed by Parasuraman et al. (1985), who suggested that service quality should be measured through the difference between expectations and the perceived service quality. The SERVQUAL scale is a multidimensional research instrument designed to evaluate service quality by assessing respondents' expectations and perceptions along five dimensions of service quality: tangibles, reliability, assurance, responsiveness, and empathy (Parasuraman et al., 1988; Zeithaml et al., 1990). The first dimension includes physical aspects concerning facilities, equipment, materials and professionals' appearance. Reliability includes issues concerning organizations 
ability to provide the promised service dependably and accurately. Assurance relates to employees' knowledge and courtesy, as well as their capability to convey confidence and trust. Responsiveness concerns the willingness to help users and to provide a prompt service. Finally, empathy refers to relational issues, including caring, and an individualized attention to users.

Although the SERVQUAL scale is not quite easily applied, neither for managers nor for researchers, because two moments of data collection are necessary (turning the process time-consuming and costly), the instrument has been widely applied, both in very different types of services, and in several geographical contexts, and has reached a wide acceptance among researchers.

However, although the SERVQUAL instrument has been widely applied in several different cross-cultural contexts, several significant criticisms have been raised concerning this approach (e.g. Van Dyke et al., 1997; Souca, 2011). For example, revisiting SERVQUAL's criticisms in literature, Asubonteng et al. (1996) highlight that ultimately, managers must be aware that the instrument is generic and thus, industries specificities need attention, and identify 2 main criticisms categories: i) model's applicability to all service industries or situations (suggesting that the variables are not consistent across industries), and ii) lack of validity, especially concerning the dependence or independence of the five main dimensions. Likewise, among other issues, Buttle (1996) identifies both operational and theoretical issues, raising concerns about whether research accurately captures preconsumption expectations, and about the questionnaire length which may induce respondents' fatigue and have potential implications concerning data reliability, in addition to time and costs involved in data collection and data analysis. The author also highlights that because the instrument should be adapted for specific contexts, which may have implications for the validity of both items and dimensions. Moreover, when research is performed in different countries, or industrial contexts, the SERVQUAL items do not always load onto the same factors.

Nevertheless, despite the several criticisms pointed in literature, the SERVQUAL instrument (or variants) has been widely used by industry practitioners, and still dominates clearly research concerning service quality. As reported by Babakus and Mangold (1992), despite criticisms on the instrument's validity and reliability, the SERVQUAL approach remains a useful and reliable tool for assessing service quality in healthcare environments.

Considering the criticism pointed out by several researchers, as an alternative to the SERVQUAL scale, Cronin \& Taylor (1992) developed the SERVPERF instrument, including the same dimensions of SERVQUAL, yet considering only users' perceptions to assess service quality. The authors argue that users' perceptions allow a better evaluation of the perceived service quality, devaluating thus previous expectations.

The SERVPERF scale is easier to use due to a reduction of questions, facilitating research, and thus promoting respondents' motivation in participating (Salomi et al., 2005), and to a better capacity to diagnose management issues, in case of possible service quality failures (Jain \& Gupta, 2004), among other issues. As reported by Cronin and Taylor (1994), reducing the number of items by half, doesn't result in a reduction of diagnostic power, yet allowing a better data accuracy through a reduction in respondents' boredom, as well as savings in terms of administration costs. Nevertheless, both SERVQUAL and SERVPERF scales mentioned above aggregate some general measures that apparently do not allow an adequate evaluation of the dimensions considered important by patients in healthcare services, as reported in literature (Santos \& Polónia, 2015).

Considering the limitations of the abovementioned scales, and mainly for cultural 
reasons, Raajpoot (2004) proposed the PAKSERV instrument, a culturally sensitive multiple-item scale, developed in a Pakistani context, organized into six dimensions, including twenty-four items. The PAKSERV scale keeps three dimensions of the SERVQUAL scale (tangibles, reliability and assurance), replacing the remaining with the introduction of three new dimensions: i) Sincerity (extent to which users evaluate employees on their ability to convince them of their intention to look after customers' interests and willingness to do something for users that goes beyond the normal call of duty, screening employees for insincerity clues of friendliness and hypocrisy), ii) Personalization (extent to which users evaluate employees on their ability to recognize users' place in the society and their importance to service business), and iii) Formality (extent to which users evaluate employees on their ability to maintain social distance by maintaining decorum, recognition of families, and by giving total attention to users) (Raajpoot, 2004).

According to Raajpoot (2004), the development of the PAKSERV scale was based on three assumptions: i) people from different cultures interpret service quality and its items differently, ii) users' expectations vary according to the cultural context and there may be more or less tolerance for the time it takes for a service to be provided, and iii) users attach importance to only a subset of service dimensions rather than all dimensions used in the model. Initially the PAKSERV scale was developed to be applied in private organizations and only in a Pakistani context; however, there are already studies applying the instrument in public organizations, and more specifically in public hospitals in Pakistan, and even in African cultural context (see Raajpoot, 2004; Saunders, 2008). Studies conducted so far have increasingly contributed to the validation of the PAKSERV scale and the authors of these investigations believe that this should be seen as a generic measurement scale which can be used across a variety of countries and cultural contexts (Saunders, 2008; Kashif et al., 2014).

\subsection{Relationship between service quality, organizational image, satisfaction and behavioural intentions}

Due to its significant growth, the services sector has become a pillar of the economy in several countries. One of the differentiating aspects of services (regarding competition) is quality, and thus it is imperative for organizations to focus on improving quality and therefore remaining on the market. Due to the importance of service quality, several investigations have been carried out, in order to conceptualize and measure service quality. However, it has not been an easy task due to the specific characteristics of the services (intangibility, heterogeneity, simultaneity of production and consumption and perishability).

In this context, and particularly in the context of healthcare organizations, service quality and user satisfaction have raised the interest of many researchers in various contexts, especially concerning their potential influence on users' attitudes and behaviours. Indeed, as such a critical factor which can become a problem for any organization that ignores it, service quality can represent a significant source of competitive advantages (Pedro et al., 2010). Moreover, according to Amin \& Nasharuddin (2013), a user is satisfied when the quality of healthcare services matches their expectations and requirements, thus reinforcing their satisfaction.

Users have their rights and choice, and if they are not satisfied with the services provided by health organizations, they have the opportunity to switch to an alternative organization. In this perspective, literature shows that some studies carried out in different healthcare contexts, in order to analyze the relationship between perceived service quality and users satisfaction, have concluded that there is a positive and significant correlation between perceived 
service quality and satisfaction, such as Raposo et al. (2009) in the context of Portuguese primary healthcare, Amin and Nasharuddin (2013) in the context of public and private hospitals in Malaysia, Faria and Mendes (2013) in the context of Portuguese healthcare centers, or Hamid et al. (2015) in the context of ophthalmology services of private hospitals in Sudan. Based on these previous evidences the following hypothesis of investigation was formulated:

Hypothesis 1: The quality of emergency services in Cape Verdean public hospitals has a significant impact on patient satisfaction.

As reported in literature, users' perception of quality not only influences the image of the organization but also contributes decisively to the image that is built in users' mind of and to the assessment that users make about the organization (Rajbhandari, 2017). The image has a functional and emotional dimension, and the functional dimension focuses on tangible aspects (easy to identify and measure), while the emotional dimension represents the psychological aspects determined by experience and the attitude of the individual regarding a specific organization (Alnaser et al., 2017). For example, Zeithaml \& Bitner (2003) point out that suggestions provided by the physical environment are instruments that allow us to communicate a purpose and image of the organization, influencing the opinion of users.

In fact, in a study conducted by Saleh et al. (2017) carried out in two Islamic banks, results show that there is a positive effect of perceived quality on the corporate image, pointing to the idea that clients with a higher service quality perception seem to form a more favourable image about the organization. Among others, several studies have been carried out in healthcare contexts, such as Faria and Mendes (2013) in the context of Portuguese healthcare centres, which suggest that perceived service quality seems to have a direct and significant effect on the image of healthcare institutions. In accordance, there are indications throughout literature suggesting that the perceived service quality may be a significant antecedent of the organizational image, including in healthcare context. Thus, the following research hypothesis is suggested:

Hypothesis 2: The perceived quality has a positive and significant impact on the image of emergency services in Cape Verdean public hospitals.

Although perceived quality in health care services is of utmost importance in patient satisfaction, several authors believe that this can result from other issues beyond perceived quality, which can be influenced by cognitive and affective causes (Rust \& Oliver, 1994; Raposo el al., 2009; Vinagre \& Neves, 2008; Faria \& Mendes, 2013). In this context, the institutional image stands out and, according to several researchers, has been highlighted as one of the most important factors for the evaluation of consumer satisfaction (Qin \& Prybutok, 2012; Faria \& Mendes, 2013; Sener, 2014; Hamid et al., 2015). As stated by Grönroos (1984), the image of an organization influences the expectations of consumers. According to Andreassen and Lindestad (1998), the image is established and developed in consumers' mind through communication and experience. Corporate image is one of the determinants in the choice of the company by the consumer when services attributes are difficult to evaluate, and if the service provided to the customer is satisfactory from his point of view, the attitudes and intentions will be favorable to the company. When service organizations are complex, the perception about quality becomes quite difficult for users; in such contexts, consumers have more confidence in their overall impressions about the organization, to draw conclusions about what they want to buy (Sener, 2014; Hamid et al., 2015; Rajbhandari, 2017). In this way, the image would appear to have a positive and significant relationship with satisfaction. 
In a research carried out in services belonging to the mobile phones industry, Tung (2010) concludes that the image of the organization has a positive influence on customers' satisfaction. In some studies carried out in different healthcare contexts examining the relationship between image and satisfaction, findings suggest positive and significant correlations between institutional image and user satisfaction, such as Sener (2014), in the context of the healthcare services of the United States of America, Faria \& Mendes (2013), in the context of the Portuguese health centers, Hamid et al. (2015) in the context of ophthalmology services in private hospitals in Sudan, or Rajbhandar (2017) in Nepalese outpatient services. Based on these assumptions, the following third research hypothesis was proposed:

Hypothesis 3: The image of emergency services in Cape Verdean public hospitals has a positive and significant impact on patient satisfaction.

As frequently reported in literature, a satisfied customer is the best seller we can find. Consumer satisfaction is generally presented as a very sensitive factor, often associated with repetitive buying processes, positive word-of-word processes, and other positive attitudes such as loyalty (Oliver, 1980; Santos \& Polónia, 2015). Satisfied clients tend to use the service more often than unsatisfied customers, manifesting new and stronger buying intentions and recommending service to their others (Zeithaml et al., 1996). Indeed, the relationship between satisfaction and behavioural intentions has been the focus of several studies conducted in several different contexts, inclusive in healthcare organizations. For example, Elleuch (2008) points out that the most common way to understand patients' behavioural intention in healthcare services starts with the wellestablished notion that when patients are very satisfied with an institution they keep dealing with this institution and transmit positive (word-to-mouth) messages to other people.
Therefore, the interaction between users and the service provider is one of the main factors in determining various types of attitudes and behaviours, such as user loyalty. In the different studies conducted, positive and significant relationships between satisfaction and various types of attitudes and behaviours have been reported, such as in Elleuch (2008) in the context of Japanese private healthcare clinics, Gaur et al. (2011) in the context of the Indian healthcare general clinics, Qin and Pributok (2012) in the context of emergency services in the United States of America, or Amin and Nasharuddin (2013) in the context of public and private hospitals in Malaysia. Thus, the following hypothesis is proposed:

Hypothesis 4: Patient satisfaction in emergency services in Cape Verdean public hospitals has a positive and significant impact on their behavioural intentions.

In addition, the various hypotheses presented above suggest that the image of public hospitals in Cape Verde can play a mediating role in the relationship between perceived quality and patient satisfaction, as observed in few previous studies such as Faria and Mendes (2013). In other words, perceived quality may also have an indirect effect on user satisfaction through the image of the institution. Therefore, the last hypothesis proposed seems perfectly reasonable:

Hypothesis 5: The image of emergency services in Cape Verdean public hospitals plays a mediating role in the relationship between perceived quality and patient satisfaction.

\section{Methods}

\subsection{Data collection and sample profile}

Data collection was conducted through a selfadministered questionnaire developed for this purpose and applied to the users of two public hospitals in Cape Verde, and was carried out between June and July 2017. 
First of all, since any research should follow strict ethical principles, aiming at protecting human rights, authorization applications were submitted both to the National Health Research Ethics Committee of Cape Verde, and to the Administration Board of each hospital unit; all applications for authorization were approved. Still concerning ethical procedures, all users were duly informed about the research's purposes, about the voluntary nature of participation, and about data confidentiality guarantee. Next, to test the questionnaire's effectiveness and efficiency as data collection instrument (assessing its consistency, and ensuring a proper interpretation by users), the questionnaire was pre-tested with six users (who were not further included in the study sample). After ensuring that the questionnaire was free from misunderstandings, the revised questionnaire was then applied in the emergency services of both institutions: Agostinho Neto Hospital (ANH) and the Baptista de Sousa Hospital (BSH).

As reported in the ANH's web page (www.han.gov.cv), located in the historical centre of the city of Praia - Santiago, ANH is the largest hospital unit in Cape Verde, occupying an area of approximately 16,832 $\mathrm{m} 2$. As a public business entity, coordinated by the Health Ministry, ANH is considered a reference hospital for Cape Verdeans, being responsible for services of great social relevance, offering comprehensive care, and providing differentiated health care. Located on the island of São Vicente, the BSH is a reference hospital for the Northern region of the country; BSH is a public institution with a special status, with its own organs, services and assets, as well as administrative and financial autonomy (see www.hospitalbaptistadesousa.cv for further details).

From a total of 700 questionnaires distributed to potential participants in the emergency services of both ANH and BSH, 308 were received (138 in ANH and 170 in $\mathrm{BSH}$ ). After a careful screening process, 4 were discarded, because they did not respect the assumptions of the study (outliers), as reported further in this paper, resulting in a final sample of 304 questionnaires retained for further analysis.

\subsection{Measurement and scale development}

Considered as a global assessment of the service provided to users, perceived service quality was measured through the PAKSERV scale developed by Raajpoot (2004). This scale approaches service quality as a multidimensional variable, incorporating twenty-four items across six dimensions, evaluated on a 5-point Likert scale, where 1 represents "Strongly Disagree" and 5 "Strongly Agree": i) 5 items for Tangibility (e.g. "Physical facilities are attractive"), ii) 4 items for Reliability (e.g. "Promises are mostly kept”), iii) 4 items for Assurance (e.g. "Employees are knowledgeable to answer users' concerns"), iv) 4 items for Sincerity (e.g. "Employees have users' interest at heart”), v) 4 items for Personalization (e.g. "Users get individual attention"), and vi) 3 item for Formality (e.g. "Employees display total attention to users"). were eliminated as they imply a Moreover, implying violation of the underlying statistical analysis assumptions (low factorial weights), 5 item were discarded, as described hereafter (2 items from Tangibility, 1 item from Reliability, 1 item from Sincerity, and 1 item from Personalization).

Considered as the extent of an emotional reaction/judgement regarding the attributes of the service provided (Oliver, 1980), users' satisfaction was measured through a three items scale, adapted from instruments used in previous studies, such as Oliver (1980), and Westbrook \& Oliver (1981). These items capture i) satisfaction based on experience, evaluated on a 5-point Likert scale, where 1 represents "Very unsatisfied", and 5 " Very satisfied", ii) satisfaction compared to expectations, evaluated on a 5-point Likert scale, where 1 represents " Much less as expected", and 5 " Much more than expected", and iii) satisfaction compared to an ideal healthcare institution, evaluated on a 
5-point Likert scale, where 1 represents "Very far from ideal" and 5 "Very close to ideal". "Considering your expectations regarding the hospital and its experience, to what extent the Hospital has fulfilled your expectations?” is an example of questions participants had to answer.

Approached as institutions' overall evaluation, the organizational image was assessed through a set of four items adapted from the European Customer Satisfaction Index model, evaluated on a 5-point Likert scale, where 1 represents "I totally disagree" and 5 "I totally agree", such as in other previous studies such as Tung (2010), or Faria and Mendes (2013): organization's i) reliability, ii) experience, iii) concerns with users, and iv) technological innovation. Items included statements such as "This is an hospital that is concerned about its users".

Directly related to users' behaviour, behavioural intention was measured through a four items scale adapted from the research performed by Zeithamlet al. (1996) and evaluated on a 5-point Likert scale, where 1 represents "Strongly Disagree" and 5 "Strongly Agree", representing i) recommendation, ii) word of mouth, iii) loyalty, and iv) preference, and including items such as "I am pleased to commend the services of this public hospital”.

In addition to these four central variables of the study (Perceived services quality, Satisfaction, Organizational Image, and Behavioural Intentions), five other variables were considered in the survey instrument in order to allow a brief characterization of the studied sample: i) gender, ii) age, iii) employment status, iv) educational background, and $v$ ) monthly net income.

Table 1 shows the mean, standard deviation and Cronbach's Alpha for each of the variables/dimensions considered in this study.

As may be observed, concerning 3 of the Perceived service quality dimensions, Cronbach Alpha's values are under 0.7 (Tangibility, Sincerity, and Formality). Generally, authors recommend a minimum level of 0.7 for Cronbach Alphas in order to assess the reliability of a multiple-item variable (e.g. Nunnally, 1978). Nevertheless, several researchers suggest 0.6 as an acceptable level for the alpha coefficient (Loewenthal, 2001; Churchill \& Peter, 1984), especially when dealing with new developed measures, or instruments applied initially in new contexts, new cultures (Nunnally, 1978). In accordance, and considering that the PAKSERV scale is being applied in a different cultural context, the reliability of Perceived service quality dimensions was considered acceptable for the research proposed.

Table 1. Mean, standard deviation, and Cronbach alpha

\begin{tabular}{|l|c|c|c|}
\hline & Mean & Standard Deviation & Cronbach \\
\hline Tangibility (T) & 3.495 & 0.494 & 0.604 \\
\hline Reliability (R) & 2.743 & 0.704 & 0.719 \\
\hline Assurance (A) & 2.983 & 0.713 & 0.787 \\
\hline Sincerity (S) & 2.805 & 0.681 & 0.648 \\
\hline Personalization (P) & 2.853 & 0.708 & 0.720 \\
\hline Formality (F) & 3.039 & 0.738 & 0.672 \\
\hline Satisfaction (S) & 2.967 & 0.803 & 0.776 \\
\hline Image (I) & 3.093 & 0.672 & 0.795 \\
\hline Behavioural Intentions (BI) & 3.257 & 0.670 & 0.736 \\
\hline
\end{tabular}

Moreover, table 2 shows the Pearson correlations between the different variables, indicating significant linear associations at the .01 level (two-tailed). 
Table 2. Correlations between latent variables

\begin{tabular}{|l|c|c|c|c|c|c|c|c|c|}
\hline & $\mathrm{T}$ & $\mathrm{R}$ & $\mathrm{A}$ & $\mathrm{S}$ & $\mathrm{P}$ & $\mathrm{F}$ & $\mathrm{S}$ & $\mathrm{I}$ & $\mathrm{BI}$ \\
\hline Tangibility (T) & 1 & $0.42^{* *}$ & $0.49^{* *}$ & $0.47^{* *}$ & $0.41^{* *}$ & $0.38^{*}$ & $0.47^{* *}$ & $0.46^{* *}$ & $0.55^{* *}$ \\
\hline Reliability (R) & $0.42^{* *}$ & 1 & $0.69^{* *}$ & $0.58^{* *}$ & $0.47^{* *}$ & $0.54^{* *}$ & $0.56^{* *}$ & $0.56^{* *}$ & $0.52^{* *}$ \\
\hline Assurance (A) & $0.49^{* *}$ & $0.69^{* *}$ & 1 & $0.60^{* *}$ & $0.52^{* *}$ & $0.58^{* *}$ & $0.59^{* *}$ & $0.60^{* *}$ & $0.60^{* *}$ \\
\hline Sincerity (S) & $0.47^{* *}$ & $0.58^{* *}$ & $0.60^{* *}$ & 1 & $0.60^{* *}$ & $0.60^{* *}$ & $0.55^{* *}$ & $0.58^{* *}$ & $0.50^{* *}$ \\
\hline Personalization (P) & $0.41^{* *}$ & $0.47^{* *}$ & $0.52^{* *}$ & $0.60^{* *}$ & 1 & $0.68^{* *}$ & $0.59^{* *}$ & $0.57^{* *}$ & $0.50^{* *}$ \\
\hline Formality (F) & 0.38 & $0.54^{* *}$ & $0.58^{* *}$ & $0.60^{* *}$ & $0.68^{* *}$ & 1 & $0.61^{* *}$ & $0.59^{* *}$ & $0.50^{* *}$ \\
\hline Satisfaction (S) & $0.47^{* *}$ & $0.56^{* *}$ & $0.59^{* *}$ & $0.55^{* *}$ & $0.59^{* *}$ & $0.61^{* *}$ & 1 & $0.66^{* *}$ & $0.68^{* *}$ \\
\hline Image (I) & $0.46^{* *}$ & $0.56^{* *}$ & $0.60^{* *}$ & $0.58^{* *}$ & $0.57^{* *}$ & $0.59^{* *}$ & $0.66^{* *}$ & 1 & $0.68^{* *}$ \\
\hline Behavioural & $0.55^{* *}$ & $0.52^{* *}$ & $0.60^{* *}$ & $0.50^{* *}$ & $0.50^{* *}$ & $0.50^{* *}$ & $0.68^{* *}$ & $0.68^{* *}$ & 1 \\
\hline
\end{tabular}

\subsection{Data analysis}

Data analysis was performed through both descriptive statistic methods (e.g. frequencies, means, standard deviation), and structural equation modelling (SEM). For such a purpose, we used two different softwares: IBM SPSS Statistics version 24.0, and IBM SPSS AMOS version 24.0.

\section{Results}

\subsection{Assumptions of the analysis methods}

The preliminary phase of data processing is essential to ensure the validity of various analysis assumptions, as well as results achieved (Hair et al., 2010). Concerning the normality assumption, as recommended by Hair et al. (2010), we used the skewness (Sk) and kurtosis $(\mathrm{Ku})$ measures of asymmetry. According to results, values of $|\mathrm{Sk}|$ ranged from 0.248 to 1.681 and the values of $|\mathrm{Ku}|$ ranged from 1.367 to 3.357, suggesting absence of assumption violation regarding univariate and multivariate normality. The linearity assumption was analysed through Pearson correlations, as suggested by Hair et al. (2010). As observed previously in table 2, excepting the relationship between tangibility and Formality, Pearson correlations between the different variables, indicate significant linear relationships at the .01 level (twotailed), suggesting thus the assumption's validity.

Multicollinearity absence means that explanatory variables are linearly independent. This assumption was verified through the tolerance value $(\mathrm{T})$ and its inverse, the variance inflation factor (VIF), as advocated by several authors (e.g. Hair et al., 2010). According to Hair et al. (2010), Ts $\geq$ 0.1 and VIFs $\leq 10$ suggest a low degree of multicollinearity. In this study, all the computed indicators indicate a low degree of multicollinearity with Ts $\geq 0.394$ and VIFs $\leq$ 2.536 .

Finally, regarding multivariate outliers, we used the Mahalanobis distance, considering a significance level of 0.001, as recommended by Hair et al. (2010). The analysis revealed 4 atypical observations that, to avoid compromising the model's fit, were withdrawn from the study.

\subsection{Validation of the measurement model}

Following the two-stage model-building approach in structural equation modelling, a confirmatory factor analysis (CFA) was applied to analyse the model measurement's validity, using for this purpose the maximum likelihood method, commonly used in these approaches due to its robustness.

Considering the several outputs generated (e.g. standardised factor loadings, fit measures report), the measuring model's factorial validity was assumed, because all the observed variables, except three (although very close to the expected limit), have high factor loadings $(\Lambda \geq 0.5)$ and suitable individual reliability $\left(\mathrm{R}^{2} \geq 0.25\right)$. 
Constructs' convergent validity was tested through several relative, absolute, and parsimony adjustment measures, considered to be the most used in research studies based on Structural Equation Models (SEM) methodology. Results obtained regarding the model's adjustment indices, assessing the quality of the hypothetical model's fit with the sample data, are summarized in table 3 .

Table 3. CFA - Model fit measures

\begin{tabular}{|l|c|c|}
\hline \multicolumn{1}{|c|}{ Fit measures } & Values & Acceptance level (Hair et al., 2010) \\
\hline Absolute measures & & $<2$ (good); <5 (acceptable) \\
\hline $\mathrm{X}^{2}$ /d.f.(CMIN/DF) & $1.796^{*}$ & $\geq 0.9$ (good); 0.95 (very good) \\
\hline GFI (Goodness of Fit Index) & 0.894 & $\leq 0.05$ (very good); 0.08 (good); 0.1 \\
\hline $\begin{array}{l}\text { RMSEA (Root Mean Square Residual Error } \\
\text { Approximation) }\end{array}$ & 0.051 & $\geq 0.9$ (good); 0.95 (very good) \\
\hline Relative measures & & $>0.936$ \\
\hline CFI (Comparative Fit Index) & & $>0.6$ (razoável); $>0.8$ (good) \\
\hline Parsimony measures & 0.723 & \\
\hline PCFI (Parsimony Comparative Fit Index) & 0.643 & \\
\hline PGFI (Parsimony Goodness of Fit Index) & & \\
\hline
\end{tabular}

$* \mathrm{X}^{2}=524.331(\mathrm{p}=0.000)$ and $\mathrm{DF}$ degrees of freedom $=292$

As may be observed, the hypothetical model has a relatively good quality fit. In fact, excepting for GFI (Goodness of Fit Index), all adjustment indices have values above the threshold values usually recommended in literature (e.g. Hair et al., 2010), suggesting a good model fit adjustment. Nevertheless, even though the GFI value is below 0.9 , it was considered acceptable because it is very close to the reference value.

\subsection{Validation of the structural model}

After the measurement model's validation, the further step focused on validating the structural model in order to analyse the different hypotheses formulated, according to which, perceived service quality would have a significant influence on users' satisfaction, with institutional image acting as mediator between both variables, and finally users' satisfaction influencing positively behavioural intentions. For this purpose, we still applied the maximum Likelihood estimation method.

As may be observed in table 4, the structural model has a reasonable fit adjustment. In fact, excepting GFI (Goodness of Fit Index), all adjustment indices' values are above references highlighted in literature (e.g. Hair et al., 2010), providing strong evidence of internal and external consistency. Moreover, even though the GFI value is below 0.9 , it was considered acceptable because it is very close to the reference value.

Table 4. Structural model fit indices

\begin{tabular}{|c|c|c|}
\hline Fit measures & Values & Acceptance level (Hair et al., 2010) \\
\hline Absolute measures & & \\
\hline $\mathrm{X}^{2} /$ d.f.(CMIN/DF) & $1.936 *$ & $<2$ (good); <5 (acceptable) \\
\hline GFI (Goodness of Fit Index) & 0.874 & $\geq 0.9$ (good); 0.95 (very good) \\
\hline $\begin{array}{l}\text { RMSEA (Root Mean Square Residual Error } \\
\text { Approximation) }\end{array}$ & 0.056 & $\begin{array}{c}\leq 0.05 \text { (very good); } 0.08 \text { (good); } 0.1 \\
\text { (poor) }\end{array}$ \\
\hline
\end{tabular}


Table 4. Structural model fit indices (Continued)

\begin{tabular}{|l|c|c|}
\hline Relative measures & & \\
\hline CFI (Comparative Fit Index) & 0.918 & $\geq 0.9$ (good); 0.95 (very good) \\
\hline Parsimony measures & & \\
\hline PCFI (Parsimony Comparative Fit Index) & 0.773 & $>0.6$ (reasonable); $>0.8$ (good) \\
\hline PGFI (Parsimony Goodness of Fit Index) & 0.684 & $>0.6$ (razoável); $>0.8$ (good) \\
\hline
\end{tabular}

${ }^{*} \mathrm{X}^{2}=615.704(\mathrm{p}=0.000)$ and $\mathrm{DF}$ degrees of freedom $=318$

Figure 1 summarizes the different relationships analysed between perceived service quality, institutional image, user satisfaction, and behavioural intentions in the context of emergency services in Cape Verde's public hospitals. Results show that perceived service quality does have a statistically significant direct effect both on patients' satisfaction ( $\beta=0.56 ; \mathrm{p}=0.018$ ), and on the institutional image $(\beta=0.83$; $p=$ $0.004)$, which in turn has also a significant direct effect on patients' satisfaction ( $\beta=$ $0.41 ; \mathrm{p}=0.019)$. In addition, findings also suggest significant direct effect of patients' satisfaction on behavioural intentions ( $\beta=$ 0.92; $\mathrm{p}=0.019$ ). Findings provide thus statistical support to hypotheses H1, H2, H3, and $\mathrm{H} 4$.

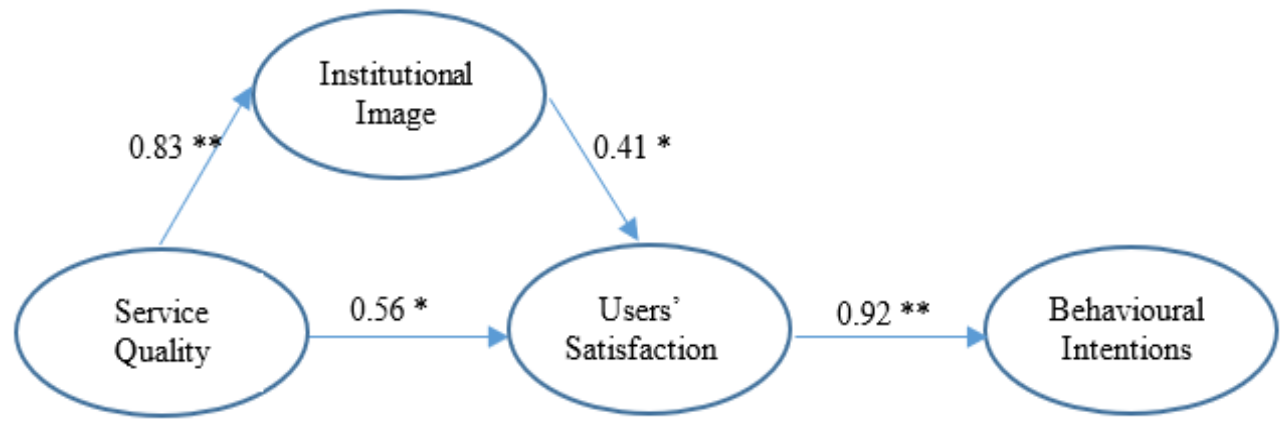

Figure 1. Structural model with standardized coefficients Notes: $* \mathrm{p}<0.05$ and ${ }^{* *} \mathrm{p}<0.01$

In order to analyse whether the institutional image mediates the relationship between perceived service quality and patients' satisfaction (Hypothesis H5), we applied a bootstrap re-sampling method due to its power in computing confidence intervals for mediating effects, as highlighted by several researchers (e.g. Shrout, \& Bolger, 2002). For such a purpose, as suggested by Cheung and Lau (2008), the number of samples was adjusted to 1000 repetitions.

According to findings summarized in Table 5, the institutional image partially mediates the relationship between perceived service quality and patients' satisfaction. Results of the bootstrap re-sampling analysis show a significant indirect effect of perceived service quality on patients' satisfaction $(\beta=0.34 ; \mathrm{p}=$ 0.012 ), suggesting thus the mediating role of the institutional image, showing that the total effect of perceived service quality on patients' satisfaction ( $\beta=0.90 ; p=0.009$ ) is significantly higher than the direct effect shown in figure $1(\beta=0.56 ; p=0.018)$. The indirect effect appears to be especially significant, as around $38 \%$ of the total effect is explained by the institutional image's mediation effect. 
ăAuTrAoH International Journal for Guality Aesearch

Table 5. Testing mediation based on AMOS bootstrapping output

\begin{tabular}{|l|c|c|c|c|}
\hline \multirow{2}{*}{ Variables } & \multicolumn{3}{|c|}{ Perceived Service Quality } & \multirow{2}{*}{ Institutional Image } \\
\cline { 2 - 4 } & Direct Effect & Indirect Effect & Total Effect & \\
\hline Institutional Image & $0.83^{* *}$ & 0 & $0.83^{* *}$ & 0 \\
\hline Users' Satisfaction & $0.56^{*}$ & $0.34^{*}$ & $0.90^{* *}$ & $0.41^{*}$ \\
\hline Behavioural Intentions & 0 & $0.83^{*}$ & $0.83^{*}$ & 0 \\
\hline
\end{tabular}

Note: Method used for bootstrap confidence intervals: bias-corrected percentile

* $5 \%$ significance level

** $1 \%$ significance level

As a result, findings support therefore hypothesis H5, according to which the image of emergency services in Cape Verdean public hospitals would play a mediating role in the relationship between perceived service quality and patients' satisfaction.

\section{Discussion and Conclusions}

Service quality researchers have been advising practitioners to use culturallysensitive scales which could bring benefits for effective management decision-making processes (e.g. Winsted, 1997). For example, the extent to which citizens of different cultures vary in their reactions to uncertainty may have a major influence on how perceived service quality affects satisfaction (Reimannet al., 2008). Although some researchers have referred the practicality of using the SERVQUAL instrument in nonWestern contexts (e,g. Ladhari, 2009), literature points to the idea that Western contexts differ from non-Western in terms of behaviour, norms, values, customs, beliefs, or political orientation (Hofstede, 1980) and, in accordance, several researchers highlight that despite its usefulness, traditional service quality assessment tools such as SERVQUAL are less useful in developing countries contexts (e.g. Tsoukatos \& Rand, 2007; Malhotra et al, 2005; Furrer et al., 2000).

Considering cultural differences between Asian and Western societies, in what service quality perceptions concerns, Raajpoot (2004) developed a culturally sensitive scale labelled PAKSERV to assess service quality in the Pakistani context, keeping tangibility, reliability and assurance SERVQUAL's dimensions but replacing responsiveness and empathy with three additional dimensions: Sincerity (e.g. unsolicited advices), Personalization (individual attention, customized solution), Formality (e.g. total attention).

Researchers have been stressing the significance of service quality and customer satisfaction for customer behaviors in service sectors; however, these relationships have rarely been tested in African contexts through culturally-sensitive scales, especially in healthcare contexts. As a result, this research contributes to the development of service management theory, first, testing the PAKSERV scale both in a different geographical context (Cape Verde), and in a different sectorial context (public hospitals), and second, analyzing the influence of service quality and users' satisfaction on behavioral intentions in the context of emergency services in Cape Verde's public hospitals.

In such a context, results of this study are also important for health institutions' administrators, suggesting PAKSERV as a potential alternative instrument for assessing service quality in non-Western cultural contexts, such as Cape Verde in particular, and possibly other African regions, in line with Raajpoot's (2004) outcomes showing that personalization, formality, and sincerity are important dimensions concerning perceived service quality in non-Western cultures.

Results show that the proposed model fits reasonably well the collected data, suggesting that, decision making in public emergency services should be grounded on a generalized consciousness that users' satisfaction is 
determinant for their behavioral intentions. Moreover, findings also confirm the significant role of perceived service quality, and especially the mediating role of the institutional image on patients' satisfaction; this is particularly important, because despite its theoretical influence in users' satisfaction, the institutional image is clearly underresearched in customer satisfaction literature (Chitty et al., 2007). Furthermore, in traditional customer satisfaction models, the institutional image is generally considered as an exogenous latent variable, influencing satisfaction but not being influenced by other factors. In line with a previous research, conducted by Faria and Mendes (2013), in Portuguese primary healthcare units, results of this research suggest clearly that institutions' image intensify the influence of perceived service quality on patients' satisfaction, through a partial mediation effect. Despite the clear lack of research concerning the role of image in users' satisfaction, especially in the health care context, a favorable institutional image is essential for users' satisfaction and positive behavioral intentions, while an unfavorable image would be adverse to user attitudes, such as word-of-mouth (Faria \& Mendes, 2013).

Concluding, this study appears to be important for managers in public health units, particularly in developing countries, insofar as it analyzes the applicability of an alternative instrument to assess perceived service quality and allows managers to understand how patients perceive quality as well as the different features that should be improved.

Of course, data explored in this research is restricted to two public Cape Verdean hospitals, and thus results should be interpreted with caution, regarding any attempt to generalize these outcomes to other African health care contexts; indeed, further studies need clearly to be conducted in other contexts in order to allow health care institutions to confidently use the PAKSERV instrument as a reliable assessment of service quality.

Acknowledgment: This paper is financed by National Funds of the FCT - Portuguese Foundation for Science and Technology within the project «UID/ECO/04007/2019»

\section{References:}

Alnaser, F., Ghami, M, Rahi, S., Mansour, M., \& Abed, H. (2017). Determinants of costomer loyalty: The role of servisse quality, customer satisfation and bank image of Islamic bank in Palestine. International Journal of Economics \& Management Sciences, 6(5), 461-464. doi: 10.4172/2162-6359.1000461

Amin, M., \& Nasharuddin, S. (2013). Hospital service quality and its effects on patient satisfaction and behavioural intention. Clinical Governance: An International Journal, 18(3), 238-254. doi: 10.1108/CGIJ-05-2012-0016

Andreassen, T., \& Lindestad, B. (1998). The effect of corporate image in the formation of customer loyalty. Journal of Service Research, 1(1), 82-92. doi: 10.1177/109467059800100107

Asubonteng, P., McCleary, K., \& Swan, J. (1996). SERVQUAL revisited: a critical review of service quality. The journal of services marketing, 10(6), 62-81. doi: 10.1108/08876049610148602

Babakus, E. W., \& Mangold, G. (1992). Adapting the SERVQUAL Scale to Hospital Services: An Empirical Investigation. Health Services Research, 26, 767-786.

Bitner, M. (1990). Evaluating service encounters: the effects of physical surroundings and employee responses. Journal of Marketing, 54(2), 69-82. doi: 10.2307/1251871 
Buttle, F. (1996). SERVQUAL: review, critique, research agenda. European Journal of Marketing, 30(1), 8-32. doi: 10.1108/03090569610105762

Carey, K., \& Stefos, T. (2011). Measuring the cost of hospital adverse patient safety events. Health Economics, 20(12), 1417-1430. doi: 10.1002/hec.1680

Cheung, G., \& Lau, R. (2008). Testing mediation and suppression effects of latent variables: Bootstrapping with structural equations models. Organizational Research Methods, 11(2), 296-325. doi: 10.1177/1094428107300343

Chitty, B., Ward, S., \& Chua, C. (2007). An application of the ECSI model as a predictor of satisfaction and loyalty for backpacker hostels. Marketing Intelligence \& Planning, 25(6), 563-580. doi: 10.1108/02634500710819941

Churchill, G. A., \& Peter, J. P. (1984). Research design effects on the reliability of rating scales: A meta-analysis. Journal of Marketing Research, 21(4), 360-375. doi: 10.2307/3151463

Cronin, J., \& Taylor, S. (1992). Measuring Service Quality: A Reexamination and extension. Journal of Marketing, 56(3), 55-68. doi: 10.2307/1252296

Cronin, J., \& Taylor, S. (1994). SERVPERF versus SERVQUAL: Reconciling performancebased and perceptions-minus-expectations measurement of service quality. Journal of Marketing, 58(1), 125-131. doi: 10.2307/1252256

Elleuch, A. (2008). Patient satisfaction in Japan. International Journal of Health Care Quality Assurance, 21(7), 692-705. doi: 10.1108/09526860810910168

Faria, N., \& Mendes, L. (2013). Organizational image's partial mediation role between quality and users' satisfaction. The Service Industries Journal, 33(13-14), 1275-1293. doi: 10.1080/02642069.2013.815733

Fradique, M., \& Mendes, L. (2013). Efeitos da liderança na melhoria da qualidade dos cuidados de enfermagem. Revista de Enfermagem Referência (Journal of Nursing), 3(10), 45-53. doi: 10.12707/RIII12133

Furrer, O., Shaw-Ching Liu, B., \& Sudharshan, D. (2000). The relationship between culture and service quality perceptions. Journal of Service Research, 2(4), 355-371. doi: 10.1177/109467050024004

Gaur, S., Xu, Y., Quazi, A., \& Nandi, S. (2012). Relational impact of service providers' interaction behavior in healthcare. Managing Service Quality, 21(1), 67-87. doi: 10.1108/09604521111100252

Grönroos, C. (1984). A service quality model and its marketing implication. European Journal of Marketing, 18(4), 36-44. doi: 10.1108/EUM0000000004784

Hair, J., Black, W., Babin, B., \& Anderson, R. (2010). Multivariate data analysis (7 $7^{\text {th }}$ ed.). New York: Prentice-Hall.

Hamid, A., Ibrahim, S., Seesy, A., \& Hasaballah, A. (2015). Interaction effect of perceived service quality and brand image on customer satisfaction. Asian Journal of Management Sciences, 3(10), 1-8.

Haywood-Farmer, J. (1993). A conceptual model of service quality. International journal of operations and production management, 8(6), 19-29. doi: 10.1108/eb054839

Hofstede, G. H. (1980). Culture's Consequences. London: Sage.

Institute of Medicine [IOM] (2000). To Err is Human: Building a Safer Health System. National Academy of Sciences. Washington (DC): National Academies Press. 
Institute of Medicine [IOM] (2001). Crossing the Quality Chasm: A New Health System for the 21st Century. Washington (DC): National Academies Press.

Jain, S. K., \& Gupta, G. (2004). Measuring Service Quality: SERVQUAL vs. SERVPERF Scales. The Journal for Decision Makers, 29(2), 25-37.

Kang, G.-D., \& James, J. (2004). Service quality dimensions: an examination of Grönroos’s service quality model. Managing Service Quality, 14(4), 266-277. doi: 10.1108/09604520410546806

Kashif, M., \& Cheewakrakokbit, P. (2018). Perceived service quality-loyalty path: A PAKSERV based investigation of international students enrolled in business schools in Thailand. Journal of Marketing for Higher Education, 28(1), 51-65. doi: 10.1080/08841241.2017.1402113

Kashif, M., Abdur Rehman, M., \& Pileliene, L. (2016). Customer perceived service quality and loyalty in Islamic banks. TQM Journal, 28(1), 62-78. doi: 10.1108/TQM-01-2014-0006

Kashif, M., Altaf, U., Ayub, H., Asif, U., \& Waslh, J. (2014). Customer Satisfaction at Public Hospitals in Pakistan: PAKSERV Application. Global Business Review, 15(4), 677-693. doi: 10.1177/0972150914543556

Kashif, M., Ramayah, T., \& Sarifuddin, S. (2016). PAKSERV - measuring higher education service quality in a collectivist cultural context. Total Quality Management \& Business Excellence, 27(3-4), 265-278. doi: 10.1080/14783363.2014.976939

Kashif, M., Shukran, S. S. W., Rehman, M. A., \& Sarifuddin, S. (2015). Customer satisfaction and loyalty in Malaysian Islamic banks: a PAKSERV investigation. International Journal of Bank Marketing, 33(1), 23-40. doi: 10.1108/IJBM-08-2013-0084

Ladhari, R. (2009). A review of twenty years of SERVQUAL research. International Journal of Quality and Service Sciences, 1(2), 172-198. doi: 10.1108/17566690910971445

Loewenthal, K. M. (2001). An introduction to psychological tests and scales ( $2^{\text {nd }}$ ed.). Hove, UK: Psychology Press, Ltd.

Malhotra, N. K., Ulgado, F. M., Agarwal, J., Shainesh, G., \& Wu, L. (2005). Dimensions of service quality in developed and developing economies: multi-country cross-cultural comparisons. International Marketing review, 22(3), 256-278. doi: 10.1108/02651330510602204

Malik, S. U. (2012). Customer Satisfaction, Perceived Service Quality and Mediating Role of Perceived Value. International Journal of Marketing Studies, 4(1), 68-76. doi: 10.5539/ijms.v4n1p68

Mendes, L., \& Fradique, M. (2014). Influence of leadership on quality nursing care. International Journal of Health Care Quality Assurance, 27(5), 439-450. doi: 10.1108/IJHCQA-06-20130069

Murti, A., Deshpande, A., \& Srivastava, N. (2013). Service Quality, Customer (Patient) Satisfaction and Behavioural Intention in Health Care Services: Exploring the Indian Perspective. Journal of Health Management, 15, 29-44. doi: 10.1177/0972063413486035

Nunnally, J. C. (1978). Psychometric theory ( $2^{\text {nd }}$ ed.). New York: McGraw-Hill.

Oliver, R. (1980). A cognitive model of the antecedents and consequences of satisfaction decisions. Journal of Marketing Research, 17(4), 460-469. doi: 10.2307/3150499

Parasuraman, A., Berry, L. L., \& Zeithaml, V. A. (1991). Understanding Customer Expectations of Service. MIT Sloan Management Review, 32, 39-48. 
Parasuraman, A., Zeithaml, V., \& Berry, L. (1985). A conceptual model of service quality and its implications for future research. Journal of Marketing, 49(4), 41-50. doi: $10.1177 / 002224298504900403$

Parasuraman, A., Zeithaml, V., \& Berry, L. (1988). Servqual: A multiple-item scale for measuring consumer perceptions of service quality. Journal of Retailing, 64(1), 12-40.

Parasuraman, A., Zeithaml, V., \& Berry, L. (1994). Reassessment of expectations as a comparison standard in measuring service quality: implications for future research. Journal of Marketing, 58(1), 111-124. doi: 10.2307/1252255

Pedro, S., Ferreira, P., \& Mendes, J. (2010). Aplicação de métodos estatisticos na avaliação da satisfação dos utentes com o internamento hospitalar [Application of statistical methods in the assessment of patient satisfaction with hospital admission]. Revista Encontros Científicos Tourism \& Management Studies, 6, 175-189.

Qin, H., \& Prybutok, V. (2012). A quantitative model for patient behavioural decisions in the urgente care industry. Socio-Economic Planning Sciences, 47(1), 50-64. doi: 10.1016/j.seps.2012.08.003

Qin, H. (2009). Links among Perceived Service Quality, Patient Satisfaction and Behavioral Intentions in the Urgent Care Industry: Empirical Evidence from College Students (Doctoral dissertation). University of North Texas.

Raajpoot, N. (2004). Reconceptualizing Service Encounter Quality in a Non-Western Context. Journal of Service Research, 7(2), 181-201. doi: 10.1177/1094670504268450

Rajbhandari, A. (2017). Measuring patients' perceived hospital service quality: A case study of Nepal's Private Hospitals. International Research E-Journal on Business and Economics, 3(1), 194-216.

Ramanujam, P. (2011). Service Quality in Health Care Organisations: A Study of Corporate Hospitals in Hyderabad. Journal of Health Management, 13(2), 177-202. doi: 10.1177/097206341101300204

Raposo, M., Alves, H., \& Duarte, P. (2009). Dimensions of service quality and satisfaction in healthcare: a patient's satisfaction index. Service Business, 3(1), 85-100. doi: 10.1007/s11628008-0055-1

Rashid, W., \& Jusoff, H. (2009). Service quality in health care setting. International Journal of Health Care Quality Assurance, 22(5), 471-482. doi: 10.1108/09526860910975580

Reimann, M., Lünemann, U. F., \& Chase, R. B. (2008). Uncertainty Avoidance as a Moderator of the Relationship between Perceived Service Quality and Customer Satisfaction. Journal of Service Research, 11(1), 63-73. doi: 10.1177/1094670508319093

Rust, R., \& Oliver, R. (1994). Service quality: Insights and managerial implications from the fronteir. In Rust, R. \& Oliver, R. (Eds), Service Quality: New Directions in Theory and Practice (pp.1-19). Thousand Oaks: Sage Publications.

Sale, D. (1998). Garantia da Qualidade nos Cuidados de Saúde, para os profissionais da equipa de saúde [Quality Assurance in Healthcare, for professionals of health team]. Lisboa: Principia - Publicações Universitárias e Científicas.

Saleh, M., Quazi, A., Keating, B., \& Gaur, S. (2017). Quality and image of banking services: a comparative study of conventional and Islamic banks. International Journal of Bank Marketing, 35(6), 878-902. doi: 10.1108/IJBM-08-2016-0111 
Salomi, G., Miguel, P., \& Abackerli, A. (2005). SERVQUAL X SERVPERF: comparação entre instrumentos para avaliação da qualidade de serviços internos [SERVQUAL X SERVPERF: comparison of instruments for evaluating the quality of internal services]. Gestão \& Produção, 12(2), 279-293. doi: 10.1590/S0104-530X2005000200011

Santos, R., \& Polónia, D. (2015). Modelo conceptual para análise da satisfação dos pacientes num serviço de urgência hospitalar [Conceptual model for the analysis of patient satisfaction in a hospital emergency service]. IMC 2015 International Management Conference, Universidade de Aveiro, $26^{\text {th }}$ June.

Saunders, S. G. (2008). Measuring and applying the PAKSERV service quality construct: Evidence from a South African cultural context. Managing Service Quality: An International Journal, 18(5), 442-456. doi: 10.1108/09604520810898820

Sener, H. (2014). Improving Patient Satisfaction in Health Services: An Application At Dumlupinar University Kutahya Evliya Celebi Education \& Research Hospital. European Journal of Business and Management, 6(30), 172-182.

Shrout, P., \& Bolger, N. (2002). Mediation in experimental and nonexperimental studies: New procedures and recommendations. Psychological Methods, 7(4), 422-445. doi: 10.1037/1082989X.7.4.422

Souca, L. (2011). SERVQUAL - Thirty years of research on service quality with implications for customer satisfaction. In Marketing - from Information to Decision, [Proceedings of the International Conference], Cluj-Napoca: Babes Bolyai University, 420 -429.

Sousa, P. (2006). Patient Safety - A necessidade de uma estratégia nacional [Patient Safety - The Need for a National Strategy]. Acta Médica Portuguesa, 19(4), 309-318. doi: 10400.21/7828

Sousa, P., Pinto, F., Costa, C., \& Uva, A. (2008). Avaliação da qualidade em saúde: a importância do ajustamento pelo risco na análise de resultados na doença coronária [Evaluation of health quality: the importance of risk adjustment in the analysis of results in coronary disease]. Revista Portuguesa de Saúde Publica, 7, 57-66. doi: 10400.21/7828

Tsoukatos, E., \& Rand, G. K. (2007). Cultural influences on service quality and customer satisfaction: evidence from Greek insurance. Managing Service Quality, 17(4), 467-485. doi: 10.1108/09604520710760571

Tu, Y., Li, M., \& Chih, H. (2011). The Effect of Service Quality, Customer Perceived Value and Satisfaction on Loyalty. Journal of Economics and Behavioral Studies, 3(3), 198-212.

Tung, F. (2010). Exploring customer satisfaction, perceived quality and image: An empirical study in the mobile services industry. The Business Review, Cambridge, 14(2), 63-69.

Van Dyke, T. P., Kappelman, L. A., \& Prybutok, V. R. (1997). Measuring Information Systems Service Quality: Concerns on the Use of the SERVQUAL Questionnaire. MIS Quarterly, 21(2), 195-208. doi: 10.2307/249419

Vinagre, M., \& Neves, J. (2008). The influence of service quality and patients emotions on satisfaction. The International Journal of Health Care Quality Assurance, 21(1), 87-103. doi: $10.1108 / 09526860810841183$

Westbrook, R., \& Oliver, R. (1981). The Dimensionality of Consumption Emotion Patterns and Consumer Satisfaction. Journal of Consumer Research, 18(1), 84-91. doi: 10.1086/209243

Winsted, F. K. (1997). The service experience in two cultures: a behavioural perspective. Journal of Retailing, 73(3), 337-360. doi: 10.1016/S0022-4359(97)90022-1

Zeithaml, V., Berry, L., \& Parasuraman, A. (1996). The Behavioral Consequences of Service Quality. Journal of Marketing, 60(2), 31-46. doi: 10.2307/1251929 
Zeithaml, V., Parasuraman, A., \& Berry, L. (1990). Delivering quality service: Balancing customer perceptions and expectations. New York: Free Press.

Zeithaml, V. A., \& Bitner, M. J. (2003). Services Marketing: Integrating Customer Focus across the Firm (3rd ed.). New York: Irwin McGraw-Hill.

\section{Vadilene Cruz}

University of Beira Interior [Master

Student],

Polo IV, Estrada do Sineiro, 6200-209

Covilhã,

Portugal

vadilenecruz@gmail.com

\section{Luis Mendes}

University of Beira Interior [Advanced Studies in Management \& Economics Research Center (CEFAGE-UBI)],

Polo IV, Estrada do Sineiro, 6200-209

Covilhã,

Portugal

lmendes@ubi.pt 